\title{
HEYDEMANN, Günther, KETTENACKER, Lothar, Kirchen in der Diktatur. Drittes Reich und SED-Staat
}

\section{Klaus Malettke}

\section{OpenEdition}

\section{Journals}

Édition électronique

URL : http://journals.openedition.org/ifha/1970

DOI : $10.4000 /$ ifha. 1970

ISSN : 2198-8943

Éditeur

IFRA - Institut franco-allemand (sciences historiques et sociales)

Référence électronique

Klaus Malettke, «HEYDEMANN, Günther, KETTENACKER, Lothar, Kirchen in der Diktatur. Drittes Reich und SED-Staat », Revue de l'IFHA [En ligne], Date de recension, mis en ligne le 01 janvier 1995, consulté le 22 septembre 2020. URL : http://journals.openedition.org/ifha/1970 ; DOI : https://doi.org/10.4000/ ifha. 1970

Ce document a été généré automatiquement le 22 septembre 2020.

(C)IFHA 


\title{
HEYDEMANN, Günther, KETTENACKER, Lothar, Kirchen in der Diktatur. Drittes Reich und SED- Staat
}

\author{
Klaus Malettke
}

Ces deux ouvrages témoignent de deux formes d'approche radicalement différentes de l'histoire du fait religieux. Le premier d'entre eux constitue le quatrième et dernier tome d'une série que H.J.S., jésuite et professeur à la Hochschule catholique de Francfort, a consacrée à l'histoire des théories conciliaires, des origines à nos jours (les trois premiers tomes ont été publiés entre 1979 et 1988). A la frontière entre l'histoire de l'Eglise et la théologie, ce volume retrace les principales étapes des réflexions de l'époque contemporaine autour du concile, de l'œuvre du théologien Bolgeni (1733-1811) jusqu'aux théories de l'après-Vatican II, en passant par l'affrontement entre la pensée libérale (Henri Maret) et l'ultramontanisme (Johann B. Heinrich) et Vatican I. De présentation à la fois claire et érudite (sans éviter toujours l'écueil du catalogue), l'ouvrage, qui comporte index et bibliographie, constitue un bon outil de travail.

Le deuxième ouvrage rassemble les communications d'une table ronde qui s'est tenue à Erfurt en décembre 1992, sous l'égide de l'Institut Historique Allemand de Londres. L'entreprise était originale: dans le contexte très particulier de l'Allemagne fraîchement réunifiée, à nouveau placée face à la nécessité de "maîtriser« son passé, il s'agissait de réfléchir sur l'attitude des Eglises protestante et catholique et des fidèles sous les deux régimes de »dictature« qu'avait connus l'espace allemand depuis 1933, le régime national-socialiste et le régime communiste de l'ancienne RDA, en bref de mener une comparaison que d'aucuns jugeaient alors encore iconoclaste. Trois thèmes ont été plus particulièrement traités: celui des relations entre Eglise et Etat, celui des relations entre théologie et idéologie politique, enfin celui des relations entre Eglise et société. Parmi les participants, on remarque les noms de H. MAIER, L. KETTENACKER, H. 
HÜRTEN ou K. NOWAK. Une solide introduction achève de faire de cette publication une invitation stimulante à poursuivre les recherches dans une voie encore peu empruntée par les historiens, Kirchenhistoriker comme historiens "profanes«.

Klaus MALETTKE 